\title{
On S, A, P, T, and R as comparative concepts for alignment typology
}

\author{
MARTIN HASPELMATH
}

\section{Abstract}

The terms $S$ (intransitive), A, $P$ (transitive), as well as $T$ and $R$ (ditransitive) have been used since the 1970s to allow linguists to characterize the differences between major alignment patterns such as accusative vs. ergative. They are often taken for granted, but a closer examination of the literature reveals that they can have three rather different meanings: in the Dixonian approach, they are used as universal syntactic functions based on transitivity; in the Comrian approach, they are seen as comparative concepts for the two arguments of a typical action clause, and in the Bickelian approach, they are taken as generalized semantic roles (Dowtyan proto-roles). In this article, I explain the three approaches in some detail, and I argue that the Comrian approach is superior to the other two approaches. It is better than the Dixonian approach because it does not take an undefined transitivity notion for granted but defines transitivity in terms of $A$ and $P$. It is also better than the Bickelian approach because the Dowtyan proto-roles were designed for the description of a particular class of English verbs; for crosslinguistic comparison, we need to limit ourselves to restricted (and semantically coherent) classes of verbs if we want to arrive at general statements.

Keywords: grammatical relations, relational alignment, semantic roles, syntax, transitivity

This article is dedicated to the memory of my friend and colleague Anna Siewierska (1955-2011), who I last met at the Zurich workshop.

\section{Introduction}

Since the 1970s, comparative linguists have often used the notions S, A, P (or $\mathrm{O}$ ), $\mathrm{T}$, and $\mathrm{R}$ (or $\mathrm{G}$ ) to compare the coding and behaviour of arguments 
in different languages, and descriptive linguists have sometimes adopted these notions or terms for describing verbal arguments in individual languages. In (1) and (2), I give some basic clauses from two languages with annotation for these notions. Apart from notational differences (P vs. O, R vs. G), the characterization of examples like these is uncontroversial, so they are a good starting point for this paper.

(1) German
a. Frau Jürgens
repariert den Porsche.
Ms Jürgens.NOM repairs the Porsche.ACC
A
V
$\mathrm{P}$

'Ms Jürgens is repairing the Porsche.'
b. Der König stirbt.
the king.NOM dies
$\mathrm{S} \quad \mathrm{V}$

'The king is dying.'
c. Herr Kramer schenkt seiner Tochter einen
$\mathrm{Mr}$ Kramer.NOM gives his daughter.DAT a
Škoda.

Škoda.ACC

A V R T

'Mr Kramer gives a Škoda to his daughter.'

(2) Ngiyambaa (Australian)

a. Miri-gu bura:y gadhi-yi.

dog-ERG child(ABS) bite-PST

A $P$ V

'The dog bit a child.' (Donaldson 1980: 132)

b. Mamie-gam-bula: Eva-gam-bula: manabi-nji.

Mamie-NAME-DU(ABS) Eva-NAME-DU(ABS) hunt-PST

S

'Mamie and Eva hunted.' (Donaldson 1980: 132)

$\begin{array}{lll}\text { c. } \quad \text { Guya=ndu } & \text { bura:y } & \text { yu- } n h i . \\ \text { fish(ABS)=you.NOM } & \text { child(ABS) } & \text { give-PST } \\ \text { T A R V } & & \end{array}$

'You gave a child fish.' (Donaldson 1980: 132)

In this article, I will describe and discuss the way in which these terms are defined and used by different linguists. For convenience, I will sometimes refer to them as "the SAPTR terms", or "the SAP terms". Although it is common for linguistic terms to be polysemous and linguists are often aware of this, it does not seem to be widely recognized yet that there are quite different and incompatible definitions of the SAPTR terms in the literature. The major goal 
of this article is to highlight the diverse uses of the terms, and I hope that in the future linguists who use them will feel compelled to provide a precise definition. A subsidiary goal is to discuss some problems and virtues of the different approaches. I will emphasize the need to distinguish between descriptive categories and comparative concepts (cf. Haspelmath 2010), a distinction that is not often made explicitly.

I distinguish three major approaches: the Dixonian approach (Dixon 1994, 2010), the Comrian approach (Comrie 1989, Lazard 2002), and the Bickelian approach (Bickel \& Nichols 2009, Bickel 2011). I will end up favouring the Comrian approach, where the SAPTR terms are used as comparative concepts, and where they are restricted to a subclass of two-argument and three-argument verbs.

Before discussing these three main approaches in detail in Sections 3 to 5, I will sketch the history of the SAPTR terms in Section 2. In the remainder of this introductory section, I will briefly explain the rationale for employing such terms (which did not exist before the 1970s) in the first place.

To make generalizations about argument properties, linguists have used syntactic functions such as subject and object since the nineteenth century. ${ }^{1}$ In (1), the Nominative NPs share a number of properties (controlling verb agreement, ordering properties, omissibility in control constructions, controlling reflexivization, and others) that make it very convenient to describe the situation in terms of a notion of Subject. We can then say that the 'repairer' argument of reparieren, the 'giver' argument of schenken, and the 'dier' argument of sterben are mapped onto this syntactic function, and a significant number of properties follow from this fact. In some special constructions, such as the Passive (3a) or the be-Applicative (3b), the mapping of roles onto syntactic functions is different, showing that the syntactic functions are independent of semantic roles.

(3) German

a. Der Porsche wird von Frau Jürgens repariert. the Porsche.NOM is by Ms Jürgens repaired 'The Porsche is being repaired by Ms Jürgens.'

1. I use the term SYNTACTIC FUnCTION for concepts like "subject" and "object" (following Dik 1997). Other equivalent terms are "grammatical relation" (Perlmutter 1980), "grammatical function" (Bresnan 2001), or "syntactic role" (Croft 2001). 
$\begin{array}{llllll}\text { b. } & \text { Herr } & \text { Kramer } & \text { be-schenkt seine } & \text { Tochter } & \text { mit } \\ \mathrm{Mr} & \text { Kramer.NOM } & \text { APPL-gives his } & \text { daughter.ACC } & \text { with } \\ \text { einem } & \text { Škoda. } & & & & \\ \text { a } & \text { Škoda } & & & & \end{array}$

'Mr Kramer gives a Škoda to his daughter.' (Lit. 'Mr Kramer gifts his daughter with a Škoda.')

In the 1970s, as systematic syntactic research on a wide variety of languages became more prestigious, it became clear that there is a problem with the older practice of extending the European subject and object concepts to all other languages. In particular, in languages with ergative constructions such as Ngiyambaa, it was not immediately clear which of the two arguments of 'bite' should be regarded as subject. Taking subject and object in a loose semantic sense, one might say that, in this language, the Absolutive case marks the intransitive subject and the (mono)transitive object, while the Ergative marks the (mono)transitive subject. But this approach would be non-rigorous and ethnocentric. As we saw in (3), the terms subject and object are not semantic notions, so a rigorous approach needs another set of concepts to describe the distribution of cases. And, equally damaging, this would be a German-centred way of describing Ngiyambaa, not better than the opposite (hypothetical) strategy of saying that the German Nominative codes both the ergative function and the intransitive absolutive function. With ditransitive clauses like (1c) and (2c), the situation is completely analogous: it is not helpful to describe Ngiyambaa in terms of the European "direct object" and "indirect object" notions, because 'child' and 'fish' are not coded analogously to German (both have Absolutive case, and there is nothing analogous to the German Dative).

This is where the SAPTR terms come in. With this novel set of terms, we can say that in German A and S are Nominative-marked and P is Accusativemarked, while in Ngiyambaa A is Ergative-marked and S and P are Absolutivemarked. The difference between the two languages (and the types they represent) can thus be characterized in a general way (i.e., not just for a few particular verbs such as 'repair' or 'kill'), without privileging the European accusative system over the Australian ergative system, and without changing the subject and object notion from a syntactic function concept to a vague semantic (macro-)role concept. This is known as ALIGNMENT typology, which is by now well-established textbook knowledge.

The terms also allow us to state crosslinguistic generalizations like those in (4) and to define some further comparative concepts like the one in (5).

(4) a. No (or almost no) language has an alignment pattern where A and $\mathrm{P}$ are treated in the same way, differently from S (Comrie 1978: 334). 
b. When alignment of flagging (i.e., case or adpositional marking) is $\mathrm{A}=\mathrm{S}$ vs. $\mathrm{P}$, usually $\mathrm{P}$ is overtly marked, and when alignment of flagging is $\mathrm{S}=\mathrm{P}$ vs. A, usually A is overtly marked (Dixon 1979: Section 2.3).

(5) A passive construction is a special construction, contrasting with a functionally less restricted active construction, in which the participant corresponding to the active $\mathrm{P}$ is expressed like the $\mathrm{S}$, and the participant corresponding to the active $\mathrm{A}$ is expressed as an oblique argument (i.e., differently from $\mathrm{A}, \mathrm{S}$, and $\mathrm{P}$ ), if at all.

It is unclear how else one might state (4) and (5), so any linguist who is interested in such generalizations and comparative concepts needs something along the lines of A, S, and P. But as we will see, there are substantial differences in the literature in the way these are understood.

The differences between the three approaches will be explained in detail in Sections 3 to 5 below, but Table 1 provides a brief overview. The distinguishing features of the Bickelian approach is that S, A, P, etc. are generalized roles and that they are applied to all verbs, whereas they are syntactic functions for Dixon and Comrie and are applied only to special subclasses of verbs. The distinguishing feature of the Comrian approach is that they are exclusively used as comparative concepts, and that the restriction to a subclass of verbs is made fully explicit.

Table 1. Three approaches to $S, A, P, T, R$

\begin{tabular}{llll}
\hline & Dixonian & Comrian & Bickelian \\
\hline Nature: & syntactic functions & syntactic functions & generalized roles \\
Scope: & (only subclass of verbs) & only subclass of verbs & all verbs \\
Purpose: & comparative + descriptive & comparative & comparative + descriptive \\
\hline
\end{tabular}

\section{A brief history of the SAPTR terms}

The three terms S, A, and O were first used in a published work in Dixon 1972, ${ }^{2}$ where they are applied to Dyirbal (1972: 59), but it is also made clear that they are universal entities that all languages have (1972: 128). Evidently, $\mathrm{S}$ is reminiscent of "subject", A is reminiscent of "agent", and O is reminiscent of "object", but Dixon does not present the terms as abbreviations of anything else.

2. Sometimes Dixon's unpublished University of London dissertation of 1968 is mentioned as the first use of the S, A, O terms, but this work was not widely used and was soon superseded by Dixon 1972. 
One suspects that the terms were inspired by Fillmore's (1968) "cases" (semantic roles as a basis for argument realization), because Fillmore, too, uses the abbreviations A and O (for "Agentive" (case) and "Objective" (case), respectively, 1968: 24-25), and he uses $\mathrm{A}$ and $\mathrm{O}$ to capture the accusative/ergative distinction (1968: 53-54).

Later in the 1970s, Dixon's usage was adopted by Blake $(1976,1977)$ and Comrie (1978), but in a modified form: Blake used $S_{i}$ (for "intransitive subject"), A, and P, and Comrie used S, A, and P. It seems that the change from $\mathrm{O}$ to $\mathrm{P}$ was made in order to make this term more parallel to the A term: just as A evokes "agent", P evokes “patient". Blake's $\mathrm{S}_{\mathrm{i}}$ (instead of S) is probably intended to avoid the impression that A could not be considered a subject (in fact, Blake (1977) also uses S, for "subject", i.e., $S_{i}+A$ ). Comrie seems to have adopted $\mathrm{P}$ from Blake's terminology, but $\mathrm{S}$ from Dixon, pointing out that it can also be taken as abbreviation of "single or sole argument" (of an intransitive verb).

In the 1980s, the SAP/SAO terms became more widely known through Dixon's (1979) overview article on ergativity and two overview books on syntactic typology (Comrie 1981 and Mallinson \& Blake 1981). Since then, this kind of alignment typology has become common textbook knowledge (though the term ALIGNMENT, introduced by Plank (1979) and picked up by Nichols (1992), is still not universally used). In 1990, Croft's overview book adopted the SAP terminology from Blake and Comrie, and added G ('goal') and T ('theme') for the two different objects of ditransitive clauses, which Dryer (1986) had shown to be parallel to monotransitive clauses in many ways: just as some constructions treat $\mathrm{S}$ and $\mathrm{A}$ in the same way (resulting in an accusative pattern, with $\mathrm{P}$ treated in a special way), and other constructions treat $\mathrm{S}$ and $\mathrm{P}$ in the same way (resulting in an ergative pattern, with A treated in a special way), we observe that some constructions treat $\mathrm{P}$ and $\mathrm{T}$ in the same way (resulting in an indirective pattern, with $\mathrm{R}$ treated in a special way, as in the German example (1c)), and other constructions treat $P$ and $G$ in the same way (resulting in a secundative pattern, with $\mathrm{T}$ treated in a special way). The similarities between monotransitive and ditransitive alignment patterns were again emphasized in Dryer 2007: 252-259 (written in 2000), and later in Haspelmath 2005a and subsequent work on ditransitive constructions such as Malchukov et al. 2010. The parallels are summarized in the figures in (6) (cf. Haspelmath 2005a; note that Dryer and Haspelmath use R instead of G). 
(6) Alignment patterns

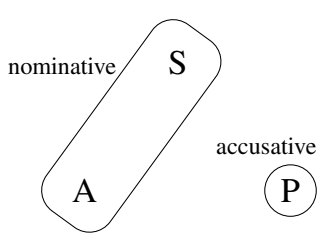

accusative alignment

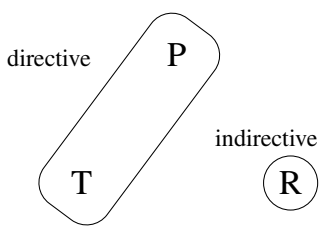

indirective alignment

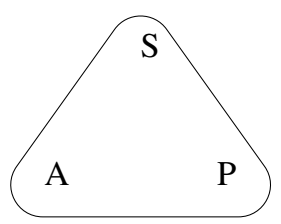

neutral alignment

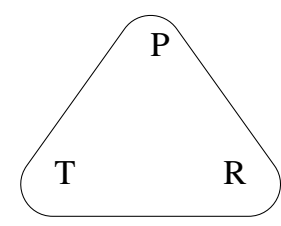

neutral alignment

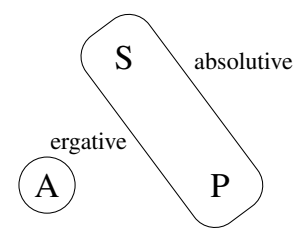

ergative alignment

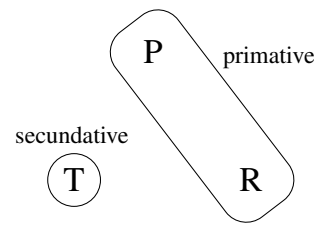

secundative alignment

Other prominent works in the 1990s and 2000s that adopted the SAP terminology are Blake 1994; Siewierska 1984, 2004; Payne 1997; Creissels 2006 (as well as Croft 2001, 2003). Dixon has continued to use SAO (Dixon 1994, 2000, 2010a, b), as have his associates (Onishi 2001, Aikhenvald 2003), as well as many of his students in their grammatical descriptions (e.g., Kruspe 2004, Guillaume 2008). The SAO terms were also adopted by Nichols (1992: 65). The PTR terminology for ditransitives was adopted as well by Siewierska (2004) and many of the contributions in Malchukov et al. (eds.) 2010.

Since the late 1970s, Gilbert Lazard has also worked on ergativity, and he has used a similar set of three letter-based terms for three notions: X corresponding to A, Y corresponding to P, and Z corresponding to S (see Lazard 1978, 1994, 1997, 1998, 2002).

There are thus some notational differences, but in general these differences do not correspond to differences in substance. Several authors explicitly say that they are just notational differences (Dixon 1994: 6, Note 4; Bickel 2011: 402). That there are also significant differences in the way the terms are understood has not been discussed in the literature, as far as I am aware, and neither has it been noticed that they have been used both as comparative concepts (for crosslinguistic comparison) and as descriptive categories for particular languages. In textbooks, A and P/O are sometimes still characterized in terms of the better-known "subject" concept (e.g., Croft 1990: 102, Whaley 1997: 156, Farrell 2005: 44), or in terms of "agent" and "patient" without further qualification (Palmer 1994: 10). 
In the next three sections, I discuss the Dixonian, Comrian, and Bickelian approaches.

\section{The Dixonian approach: $\mathrm{S}, \mathrm{A}, \mathrm{O}$ as universal syntactic functions}

For R. M. W. Dixon, the terms A, S, and O refer to universal syntactic functions, much like the grammatical relations 1, 2, and 3 in Relational Grammar (Perlmutter 1980, Blake 1990), or like subject and object in Lexical-Functional Grammar (Bresnan 2001, Falk 2006). This position has not changed over the years:

All languages appear to have transitive and intransitive sentences, and thus to involve the three syntactic functions 'transitive subject [A]', 'transitive object [O]' and 'intransitive subject [S]'. (Dixon 1972: 128)

For any discussion of universal grammar, it is most useful to take $\mathrm{S}, \mathrm{A}$ and $\mathrm{O}$ as the basic grammatical relations [...] (Dixon 1994: 6-7)

Within a cross-linguistic typology, it is most useful to take $\mathrm{S}, \mathrm{A}$ and $\mathrm{O}$ as universal syntactic relations. (Dixon 2010a: 76)

Dixon has used these terms both for comparative purposes (e.g., Dixon 1979, 1994, 2000) and for language-particular description (e.g., Dixon 1972, 1988; Dixon with Vogel 2004), and quite a few other linguists have used S, A, and O for grammatical description (e.g., Donohue 1999, Guillaume 2008, Schapper 2009).

As noted by Lazard (1997), Dixon is not always very clear about the status of the notions as syntactic functions (he sometimes calls them "semantic-syntactic categories"), and it is clear that the distinction between A and $\mathrm{O}$ is to some extent semantically grounded: "that argument whose referent is most likely to be relevant to the success of an activity is identified as A" (Dixon 2010b: 116). But there are two ways in which $\mathrm{A}$ and $\mathrm{O}$ are clearly syntactic functions like subject and object, not semantic roles or role clusters:

First, valency-changing operations change the syntactic function of a verb. For example, "antipassive places the deep A NP in surface S function, and marks the deep O NP with an oblique case/preposition/etc." (Dixon 1979: 119; similarly Dixon 2010b: 166). And "causative adds a new A argument (prototypically to an intransitive clause - the old $\mathrm{S}$ becoming $\mathrm{O}$ - often also to a transitive)" (Dixon 2000: 31).

Second, S, A, and O are identified not only on the basis of semantic roles and coding of arguments, but also on the basis of behavioural properties (crossclausal constructions, reflexivization, valency-changing, Dixon 2010b: 118). This means that the coding properties of $\mathrm{A}$ and $\mathrm{O}$ can be irrelevant, and we may have "non-canonically marked A and O" (Aikhenvald et al. (eds.) 2001, 
Dixon 2010b: 52-54). For example, Avar has a dative-marked A with some experiential verbs, and Yawuru has a dative-marked $\mathrm{O}$ with some verbs (Dixon 1994: 121). In this respect, A is much like "subject (of a transitive clause)" in generative syntax, where coding properties are widely regarded as "superficial" and not decisive for determining the syntactic function (e.g., Anderson 1976 and much subsequent work).

But since the mid-1970s (Blake 1976, Schachter 1976, Foley \& Van Valin 1977), linguists have known that the subject function is not universal, and this clearly applies to syntactic functions in general (Dryer 1997, Croft 2001, Lazard 2006). Syntactic functions are defined and identified by different criteria in different languages, so they cannot be equated across languages. ${ }^{3}$ In the same way, S, A, and O cannot be used as crosslinguistic categories. Otherwise, it should be possible to give them a crosslinguistically applicable definition, but Dixon never provides one.

Basically, $\mathrm{A}$ and $\mathrm{O}$ are defined as core arguments ${ }^{4}$ of a transitive clause, but Dixon gives no definition of "transitive clause". However, there are many twoargument clauses that do not seem to be transitive, or that at least are not clearly transitive (cf. also McGregor 2002: 292). Throughout the 1980s and 1990s, such clauses played no role in Dixon's writings. Consider the two-argument clauses in (7) from Lezgian (Haspelmath 1993: 268-293). Only the first has a canonical Ergative-Absolutive coding pattern.

a. Ergative-Absolutive

Sadiq'-a jad $q^{h}$ wa-na.

Sadiq'-ERG water(ABS) drink-AOR

'Sadiq' drank water.' (Haspelmath 1993: ex. 137)

b. Ergative-Dative

Ajal-r-i muallim.di-z hürmet-zawa.

child-PL-ERG teacher-DAT respect-IMPF

'The children respect the teacher.' (Haspelmath 1993: ex. 757a)

3. For example, subjects are usually defined by Nominative case marking and agreement in Latin and German, but many languages do not have case-marking and/or agreement, or there is no "nominative" case, or there are several different agreement patterns, and so on. If one then resorts to rather different criteria such as word order and constituency (as is often done for Icelandic Dative "subjects"), one ends up with a category that one may call "subjects", but that is clearly a different category.

4. Dixon (2010a: 97) briefly characterizes core arguments as arguments that "must be either stated or understood from the context" (as opposed to peripheral arguments, which are optional). Thus, by "core vs. peripheral argument", he means what is generally known as "arguments vs. adjuncts". 
c. Dative-Absolutive

Za-z sa ktab žğa-na.

I-DAT one book(ABS) find-AOR

'I found a book.' (Haspelmath 1993: ex. 744a)

d. Dative-Postelative

Šarwili.di-z ada-qhaj kič'e $\hat{x} a-n a-c ̌$.

Šarwili-DAT he-POEL afraid be-AOR-NEG

'Šarwili was not afraid of him.' (Haspelmath 1993: ex. 746a)

e. Absolutive-Adessive

Mašin-ar xürü-w agaq'-na.

car-PL[ABS] village-ADESS reach-AOR

'The cars reached the village.' (Haspelmath 1993: ex. 724b)

Are these all transitive clauses? Dixon does not seem to be interested in arguments which are expressed by oblique noun phrases, but they cannot be simply left aside like adjuncts, because they are obligatory, or if omitted, are understood from the context (see Footnote 4), so they must be (core) arguments. Probably nobody would want to say that all two-argument clauses are transitive, because in that case even clauses with a locational argument (She went to town) or with a symmetrical argument (He wrestled with a dragon) would be transitive. But such clauses normally show quite different coding properties, and the ergative/accusative distinction that motivated the SAP notions in the first place was never intended to apply to them.

The general problem is that there are no crosslinguistically applicable syntactic criteria for identifying (mono)transitive clauses - typological work such as Hopper \& Thompson 1980, Kittilä 2002, and Næss 2007 has relied on semantic prototype definitions that do not allow precise delimitation of transitive clauses from non-transitive clauses. In individual languages, precise criteria for distinguishing two major clause types ("transitive", "intransitive") can often be found (e.g., particular argument-indexing patterns, passivizability, or even inflectional classes), but they are quite diverse and not generalizable across languages. Dixon's strategy of simply assuming that transitive and intransitive clauses can be identified in any language cannot be successful.

Most linguists agree that there are two-argument clauses which are intransitive, and in more recent work, Dixon has recognized an intransitive clause type with an S argument and an additional argument called $\mathrm{E}$ (for "extension to core") (Dixon \& Aikhenvald (eds.) 2000; Dixon 2010a, b). He illustrates this with examples from Tongan (Dixon 2010a: 99, 2010b: 117; no source is given for the Tongan data).

$$
\begin{aligned}
& \text { a. Na'e 'alu 'a e fefiné. } \\
& \text { PST go ABS ART woman } \\
& \text { 'The woman (S) went.' }
\end{aligned}
$$




b. Na'e taa'i 'a e tangatá $e$ he fefiné.
PST see ABS ART man ERG ART woman
'The woman (A) hit the man (O).'
c. Na'e sio 'a e fefiné ki he tangatá.
PST see ABS ART woman DAT ART man
'The woman (S) saw the man (E).'

Dixon says that the (8c) clause is intransitive (with S and E, rather than A and $\mathrm{O})$, because the perceiver argument shows the same grammatical properties as the $\mathrm{S}$ argument in the plain grammatical sentence. But one could equally say that Tongan has two types of transitive clauses with $\mathrm{A}$ and $\mathrm{O}$, one with an ergative pattern (8b) and one with an accusative pattern (8c). A similar reasoning would lead us to assign the functions $\mathrm{S}$ and $\mathrm{E}$ to the two arguments in the Lezgian clause (7e), but what to do with (7c), and especially with (7d), would still be unclear. (See also Witzlack-Makarevich 2011: Section 7.2 for a similar critique of Dixon.)

Why have these unclarities not prevented Dixon's approach from being widely cited and adopted? It seems that Dixon and his readers focused their attention on typical transitive clauses with verbs like 'kill' or 'break', as exemplified by the well-known Dyirbal clause balan dy ugumbil bangul yarangu balgan 'man is hitting woman' (Dixon 1972: 59). For a long time, other twoargument clauses were simply left aside, not only by Dixon, but also by other researchers who were grappling with similar issues. It is easy to find typical transitive clauses in every language, and they are clearly a very prominent clause type, so that an intuition-based definition of transitivity has generally sufficed. And the function-changing alternations of passive, antipassive, causative, and applicative also seemed to work in terms of $\mathrm{A}$ and $\mathrm{O}$ as defined loosely by Dixon.

\section{The Comrian approach: $A$ and $P$ as comparative concepts for the two arguments of typical transitive clauses}

A way of preserving Dixon's most important insights, while at the same time eliminating the weaknesses of his approach, is to say explicitly what has perhaps been implicit in Dixon's work: that A and P can be identified readily only for typical transitive clauses (i.e., clauses with physical effect verbs like 'kill' or 'break'), while other two-argument clauses are not considered in this context. In effect, it says that transitive clauses of the 'kill' or 'break' type are the typical two-argument clauses. This approach would arrive at the same conclusions as Dixon for the typical clauses as in (1) and (2), but would not say anything about atypical clauses like (7b-e) from Lezgian or (8c) from Tongan. At first, it appears that this makes this approach less comprehensive, and one may wonder how it could be extended to atypical two-argument clauses. The answer is two-fold. 
First, from a crosslinguistic perspective, the limitation to typical transitive clauses is no problem, because atypical two-argument clauses differ drastically across languages anyway, and in practice, knowing that a language has a dominant accusative ( $\mathrm{A}=\mathrm{S}$ vs. $\mathrm{P}$ ) or ergative (A vs. $\mathrm{S}=\mathrm{P}$ ) pattern does not tell us anything about the atypical two-argument clauses. In particular, the treatment of arguments of experiential verbs (as in (7c, d), (8c)) is quite different across languages (e.g., Bossong 1998), but it does not seem that these differences can be predicted from the differences in the treatment of typical transitive clauses. Thus, typologists must come up with something special for experiential clauses anyway.

Second, from a language-particular perspective, we simply do not need the SAPTR terms. For German, for example, it is quite acceptable and in fact common practice to work in terms of syntactic functions such as "Nominative argument", "Accusative argument", "Genitive argument", "Prepositional phrase argument", etc. (e.g., Engel 1988). Asking which of these is the "subject" is not necessary (Reis 1982). For English, it is not necessary to distinguish between A and S either (because the transitive Subject and the intransitive subject behave alike). For Dyirbal, we can follow Dixon (1972) and say that there is a Deep Subject function that is occupied, for instance, by the hittee argument of 'hit', the comer argument of 'come', the hitter argument of the Antipassive form of 'hit', and so on. Presented in this way, the three languages are difficult to compare, and it is precisely for comparative purposes that the SAPTR terms were originally created. But language-particular description is not aided by these terms (except in the trivial sense that a typologically-oriented description may well be easier to understand, even if is less elegant and less faithful to the inner workings of the language).

A definition of $\mathrm{A}$ and $\mathrm{P}$ along these lines that is based on only a subclass of transitive clauses is given by Comrie (1981: 105, 1989: 111): ${ }^{5}$

In the prototypical transitive situation, the participants are an agent and a patient, and this remains constant irrespective of the morphological or syntactic behaviour of the sentence in any individual language. We may therefore, starting originally with transitive predicates describing actions, label the agent as A, and the patient as P, so that in the sentence I hit you [...] irrespective of the case marking of the various noun phrases $I$ will be A and you will be P. [... W] can continue to use [A and $\mathrm{P}]$ even when we pass beyond prototypical transitive situations (i.e. actions) to other constructions [...] A and $\mathrm{P}$ are thus syntactic terms, whose prototypes are defined in semantic terms.

5. Note that Comrie (1978) did not give this prototype-based definition yet: A was defined as "that argument of a transitive verb that would be its subject in a non-Ergative language like English", and P was "the argument that would be the direct object" (Comrie 1978: 330-331). 
Indeed, it seems to be the case that in all languages, two-argument verbs with typical agents and patients are treated in the same way, i.e., we never find significant variation in the coding of verbs like 'kill', 'break', 'cut', 'beat', 'burn', 'grind', 'saw', 'wash'. 6

Similarly to Comrie, Andrews $(1985,2007)$ starts out with the class of "primary transitive verbs" (PTVs), i.e., verbs with typical agents and patients, which "play a fundamental role in all languages" (Andrews 1985: 68). He then defines $\mathrm{A}$ and $\mathrm{O}$ as follows:

If an NP is serving as argument of a two-argument verb, and receiving the morphological and syntactic treatment normally accorded to an Agent of a PTV, we shall say that it has the grammatical function $\mathrm{A}$; if it is an argument of a verb with two or more arguments receiving the treatment normally accorded to the Patient of a PTV, we shall say that it has the grammatical function $\mathrm{O}$.

The most explicit justification of the idea that A and P should be defined with respect to a prototypical action is given in Lazard 2002. ${ }^{7}$ Like Comrie and Andrews, Lazard notes that there is a robust crosslinguistic generalization underlying A and $\mathrm{P}^{8}$ the construction expressing a prototypical action ${ }^{9}$ (what he calls the "major biactant construction" $"$ ) has proved to "occupy a special place in the grammar of most (or all) languages" (Lazard 2002: 153). He also notes that the valency frame of these verbs can justifiably be called "major biactant construction" because in very many languages, it is also used for verbs that express situations other than prototypical actions. For example, many languages use this construction also for verbs of perception (e.g., in Dyirbal, 'mother saw father' is yuma yabu-ygu buran [mother father-ERG saw], Dixon 1994: 10),

6. Even though lexeme-based splits are thus excluded by this approach, there are of course still splits based on referential properties of the NP (pronoun vs. full noun, animate vs. inanimate, etc.), on tense and aspect, and so on (as discussed in detail by Witzlack-Makarevich 2011 and elsewhere). This means that alignment in the traditional sense can only be determined within such domains, not across them. Thus, Comrie (2005) treats alignment of case marking separately for full nouns and pronouns.

7. Surprisingly, Lazard (2002) does not refer to Comrie $(1981,1989)$ or Andrews (1985). It is quite possible, however, that he arrived at very similar conclusions independently (perhaps in the sense that by the 1990s, the Comrian use of A and P was well-entrenched in the field, even though few people had made the definitions of these concepts explicit).

8. Recall that Lazard uses $\mathrm{X}$ and $\mathrm{Y}$ instead of $\mathrm{A}$ and $\mathrm{P}$, but this is a purely notational matter that I will ignore in the following.

9. This is defined as "an effective volitional discrete action performed by a controlling agent and actually affecting a well individuated patient", e.g., The hunter killed the rabbit (Lazard 2002: 152).

10. The term "biactant" simply means "two-argument". In the tradition of Tesnière (1959), Lazard uses ACTANT for what is called ARGUMENT here. I agree with Lazard that ACTANT is in principle preferable to ARGUMENT (cf. Lazard 1997: 247), but I use ARGUMENT because the term is now so well entrenched. 
and in some languages, we find the major biactant construction used even in situations that have hardly any similarity to prototypical actions, e.g., (9).
a. French
L' école jouxte la mairie.
the school is.next the town.hall
'The school is beside the town hall.'
b. French
La chambre sent la pomme. ${ }^{11}$
the room smells the apple
'The room smells of apples.'
c. This room sleeps four persons.

However, the further we go from prototypical (physical-effect) actions, the more variation there is across languages (Tsunoda 1985, Malchukov 2005). With perception verbs like 'see', there is some variation (cf. Bossong 1998), though most languages seem to be like English and Dyirbal in using their major biactant construction for them. In cases like (9), there is so much variation that even French and English, two languages that are otherwise very similar typologically, have different constructions.

On the basis of the notion of the major biactant construction, Lazard then defines A as the argument of this construction that represents the agent when the construction expresses an action, and $\mathrm{P}$ as the argument that represents the patient when the construction expresses an action. This is fully compatible with Comrie's and Andrews's definitions, only somewhat more elaborate. Another author who provides a definition of $\mathrm{A}$ and $\mathrm{P}$ in the same terms is Creissels (2006: 283). ${ }^{12}$

11. It should be noted that in these discussions only coding properties are taken into account, and (9b) clearly shows the same coding properties as other transitive clauses in French. It differs from them in some behavioural properties, as noted, e.g., by Melis (2002: 62) - for example, (9b) cannot be passivized. This is a general fact about Comrian A, S, P, T, R: they are defined with respect to coding properties, not behavioural properties.

12. A reviewer is worried that the definitions of the crosslinguistic concepts A and P thus presuppose a crosslinguistic generalization (namely that there is no variation in the coding of typical physical effect verbs) that is not firmly established. But if it turned out that a language has two different constructions for typical action verbs, this would just mean that there would be two different instances of A and P. This is not desirable, because it makes crosslinguistic comparison more complicated, but it is not an inconsistency. In fact, a very similar situation commonly arises with intransitive $\mathrm{S}$, which is often coded differently with different verbs (see Section 7). So the observation that languages strongly tend to have only a single major biactant construction is not a precondition for the viability of the definitions, but merely an argument in favour of their usefulness. (A well-known language which has two major biactant constructions is Tagalog, and the resulting impossibility of subsuming the language under the classical alignment types is well known.) 
What the Comrian approach shares with the Dixonian approach is that A and $\mathrm{P}$ are conceived of as syntactic functions, so that it is possible to say that in passivization, the $\mathrm{A}$ becomes an oblique, and the $\mathrm{P}$ becomes an $\mathrm{S}$ (Comrie 1989: 114, Lazard 2002: 159). ${ }^{13}$

But it is crucially different from the Dixonian approach in that it does not try to define $\mathrm{A}, \mathrm{S}$, and $\mathrm{P}$ on the basis of transitivity, but it is the other way round: a transitive clause is one with $\mathrm{A}$ and $\mathrm{P}$, and an intransitive clause is one that lacks A and P (Andrews 1985: 68, Blake 1994: 206, Creissels 2006: 284) ${ }^{14}$ As we saw that Dixon was unable to give good independent criteria for identifying transitive clauses, this is an important advantage.

Moreover, in the Comrian approach, $\mathrm{A}$ and $\mathrm{P}$ of transitive clauses are by definition marked "canonically". "Non-canonically marked" A and P, as they exist for Dixon, are impossible for Comrie, Andrews, Lazard, and Creissels. In clauses like (10a, b) from German, Dixon would probably say that 'the boy' is in A function in both cases, while 'the baby' is in O function, and that both NPs in (10a) and 'the baby' in (10b) are marked non-canonically.
a. Dem Jungen gefällt das Baby. the boy.DAT pleases the baby.NOM
'The boy likes the baby.'
b. Der Junge hilft dem Baby. the boy.NOM helps the baby.DAT 'The boy is helping the baby.'

In the Comrian approach, none of the arguments of these clauses would be A and $\mathrm{P}$, because they do not use the major biactant construction. Hence both clauses would qualify as intransitive.

Now of course if "intransitive" is no longer defined as "containing a single argument" (as in Dixon's work, at least until the introduction of "extended

13. Note that this was not so clear yet in Comrie 1978: on the one hand, Comrie said in that paper that in the antipassive, A becomes S (1978: 363), but on the other hand, he said that in the passive clause John was kissed by Mary, Mary is A and John is P (1978: 368). Here A and $\mathrm{P}$ seem to have been used as generalized semantic roles, as in the Bickelian approach, not as syntactic functions. Likewise, Comrie (1978: 375-376) applied A and P to nominalizations like Russian razrušenie gorod-a vrag-om [destruction city-GEN enemy-INS] 'the city's destruction by the enemy', where he said that P stands in the genitive, while A stands in the instrumental. Again, here A and $\mathrm{P}$ were used in a different, more semantic sense. (This latter usage of the SAP terms was adopted by Koptjevskaja-Tamm 1993.)

14. A reviewer notes that it is circular to define transitivity in terms of A and P (as proposed by myself), and at the same time to define A and P in terms of "prototypical transitive situations", as is done in the Comrie quotation above. This is true, and therefore I recommend following Andrews $(1985,2007)$ and Lazard (2002) in defining A and P in terms of prototypical actions with two participants, not in terms of transitivity. 
intransitive" clauses like (8c)), we also need a new definition of S. Such a definition is provided by Andrews (1985: 68):

An NP in an intransitive sentence that is receiving the treatment normally accorded to the single argument of a one-argument predicate will be said to have $\mathrm{S}$ function.

Thus, in (10a) das Baby is $\mathrm{S}$, while in (10b) der Junge is $\mathrm{S}$ (because both are in the nominative case). Nothing is said about the non-S arguments of intransitive clauses (which would be E in Dixon's approach), which is just as well, because the various non-S arguments do not seem to have much in common.

Linguists who seem to have adopted the Comrian approach often define A and $\mathrm{P}$ in terms of similarity of the argument's role to the agent and patient roles:
a. Payne
A
(1997: 75)
"most agent-like
argument of a
transitive clause"
b. Dryer
"the more agent-like
(2007: 252)
argument in a
transitive clause"
c. Haspelmath
"most agent-like
(2009: 512)
argument of a
transitive clause"
$\mathrm{P}$
argument of a
transitive clause"
"the more patient-like
argument [in a
transitive clause]"
"most patient-like
argument of a
transitive clause"
"least agent-like

However, even though such short definitions of A and P are convenient, they are not accurate. In the definitions in (11), transitivity is used as a definiens, although it must itself be defined in terms of A and P, as we saw. Moreover, the definitions in (11) do not make it clear in what way non-agent A arguments (like l'école, la chambre, this room in (9)) are more agent-like than the corresponding $\mathrm{P}$ argument. Do these authors mean that the semantic role of such arguments is more similar to the agent role than the role of the $\mathrm{P}$ argument? In that case, their definitions would characterize generalized semantic roles, which is not what the Comrian A and P are. Or is "agent-like" another way of saying that the A argument is treated morphosyntactically like an agent? In the latter case, the comparative ("more/most agent-like")) would be misleading one should simply say that "the A is the morphosyntactically agent-like argument". ${ }^{15}$ But this is too short to be fully clear. To get an accurate definition,

15. Another way of making the short definitions in (11) more accurate would be to replace "transitive" by "typical action": "A is the agent argument of a typical action clause" (Comrie's (2005: 398) definition comes close to this). The fact that other, non-agent arguments are coded in the same way would not be covered by this definition, but in many comparative contexts this is not important. 
one needs Lazard's notion of major two-argument construction (unfortunately, the definitions are not particularly short):

A

"the argument of the major twoargument construction that represents the agent when the construction expresses an action"

\section{$\mathrm{P}$}

"the argument of the major twoargument construction that represents the patient when the construction expresses an action"

It should be apparent from this discussion that the Comrian concepts $\mathrm{A}, \mathrm{S}$, and $\mathrm{P}$ are comparative concepts, and are not really suitable as descriptive categories of particular languages. This becomes clear as soon as one extends one's purview beyond prototypical two-argument clauses. For example, Icelandic provides robust evidence for a "Subject" function that encompasses not only A and S arguments, but also a substantial number of oblique-marked NPs (e.g., Andrews 2001). From the point of view of Icelandic, there is no particular reason to privilege A and S, and the notion of "major biactant construction" need not play any role in the description of the language. But to compare Icelandic with other languages, we do need A and S. Whereas Dixon sees his concepts as part of Basic Linguistic Theory, a descriptive framework that can be used to describe any language, the Comrian concepts are primarily used for comparative purposes. The arguments of non-prototypical two-argument verbs will eventually have to be drawn into the comparison, but it may well be that they show so much idiosyncrasy that not many generalizations of the type in (4) and (5) will be found.

That $\mathrm{S}, \mathrm{A}$, and $\mathrm{P}$ are comparative syntactic functions and crucially different from the descriptive syntactic functions that a language-particular analysis would adopt was noted early on by Goddard (1982: 181-184), who argued against the view that Dixon's S, A, and O are syntactic categories or syntactic functions and preferred to label them "language independent syntactic CONTEXTS" (1982: 182), i.e., etic comparative concepts. He acknowledged their value to linguistic typology but disputed their value to description. Andrews (1985: 66, 2007: 134) makes a distinction between "grammatical functions" like A, S, and O and "grammatical relations" like Subject and Object in English. Only a grammatical relation is something that is "generally significant for the workings of the grammatical principles" of a particular language. And McGregor (2002: 292-293) criticizes Dixon's A, S, and O, but notes (2002: Note 2) that his criticism applies "specifically to the S-A-O theory in its emic interpretation", not when these terms are used as "etic conveniences" in typology. 


\section{The Bickelian approach: $\mathrm{S}, \mathrm{A}, \mathrm{P}, \mathrm{T}$, and $\mathrm{G}$ as generalized semantic roles}

The SAPTR terms are often seen as "a sort of compromise between thematic roles and grammatical relations" (Koptjevskaja-Tamm 1993: 12), and Dixon used to call them "semantico-syntactic roles" (1979: 61). But in fact, as we saw, they are syntactic functions both in the Dixonian and in the Comrian approach, even though the definition of the functions has a semantic dimension.

Since the syntactic functions have an important semantic dimension, it is easy to give a different sense to the SAP terms, namely as referring to the semantic dimension itself, or in other words to generalized semantic roles. In Hopper \& Thompson's (1980) well-known theory of transitivity, A and O are the terms for "the two participants in a two-participant clause" (Hopper \& Thompson 1980: 252), and they say explicitly that they use the terms differently from Dixon: "We make no claims about the grammatical relations that the NP arguments referring to these partcipants might bear to the verb". Næss (2007: 7) likewise uses A and $\mathrm{O}$ for the two participants of a two-participant clause, regardless of the formal coding, in explicit contrast to Dixon.

Mithun \& Chafe (1999) discuss S, A, and O in the context of alignment typology and interpret them as generalized semantic roles, as seems clear from the alternatives that they present: they actually argue AGAINST S, A, and O, and instead favour the information-structural function of starting point (for $\mathrm{S}+\mathrm{A}$ ), the semantic roles agent (for $\mathrm{A}$ and agentive $\mathrm{S}$ ) and patient (for $\mathrm{O}$ and patientive S), and the notion of immediate involvement (for S+O). ${ }^{16}$ Kibrik's (1997: 290) interpretation is very similar - he talks about "the hyperroles Agentive (A) and Patientive $(\mathrm{O} / \mathrm{P})$ ".

This use of the letter terms S, A, P, T, and G for generalized semantic roles, which are in stark contrast to grammatical relations, is clearest in recent work by Bickel and associates (Nichols 2008, Bickel \& Nichols 2009, Bickel et al. 2010, Bickel 2011, Witzlack-Makarevich 2011). These generalized roles are defined as in (13), with different roles for the three types of numerical valency (Bickel \& Nichols 2009: 307, Bickel et al. 2010: 384):

a. One-place predicates:

$\mathrm{S}$ the sole argument of a one-place predicate

16. Mithun \& Chafe evaluate $\mathrm{S}, \mathrm{A}$, and $\mathrm{O}$ as descriptive categories for the analysis of particular languages (their examples are English, Seneca, and Yup'ik) and find them wanting: "Alternative patterns are not simply a question of alternative structural 'alignments', but the result of the grammaticization of distinct ways in which referents may be related to events and states" (Mithun \& Chafe 1999). They do not seem to realize that Comrian A, S, and P are used as purely comparative concepts, not implying anything about the optimal language-particular analysis. 
b. Two-place predicates:

$\mathrm{A}_{1}$ the more agent-like argument of a two-place predicate

$\mathrm{P}$ the less agent-like argument of a two-place predicate ${ }^{17}$

c. Three-place predicates:

$\mathrm{A}_{2}$ the most agent-like argument of a three-place predicate

$\mathrm{G}$ the more goal-like (or patient-like) argument of the nonagent-like arguments of a three-place predicate

$\mathrm{T}$ the less goal-like (or patient-like) argument of the nonagent-like arguments of a three-place predicate

At first glance, the definitions look much like the simplified definitions of Comrian A, S, and P (see (11) above), but there is a big difference. While Comrie, Blake, Dryer, Lazard, Siewierska, and others (sometimes implicitly) limit A and $\mathrm{P}$ to typical transitive clauses, for Bickel and his associates there is explicitly no such limitation: $A_{1}$ and $P$ apply to all two-argument verbs. Similarly, while Malchukov et al. (2010) limit A, T, and R in ditransitive clauses to transfer verbs ('give', 'send', etc.), Bickel et al. (2010) apply $A_{2}, \mathrm{G}$, and T to all three-argument verbs. The scope of the generalized semantic roles is thus significantly greater than the scope of Comrian S, A, P, T, R.

But as a consequence, while the Bickelian approach agrees with the Dixonian and the Comrian approach in the assignment of labels to our initial examples in (1) and (2), it differs strikingly from them with other verbs, as illustrated in (14).
$\begin{array}{lll}\text { a. The woman went to town. } \\ \mathrm{A}_{1} & \mathrm{~V} \quad \mathrm{P}\end{array}$
b. German
Mir graut vor dem Examen.
I.DAT dreads of the exam
$\mathrm{A}_{1} \quad \mathrm{~V} \quad \mathrm{P}$
'I am dreading the exam.'
c. She covered you with an umbrella.
$\begin{array}{llll}\mathrm{A}_{2} & \mathrm{~V} & \mathrm{G} & \mathrm{T}\end{array}$
d. You cut wood with a saw.
$\mathrm{A}_{2} \quad \mathrm{~V} \quad \mathrm{G} \quad \mathrm{T}$

An argument is regarded as agent-like to the extent that is has one or more of the agent properties in (15a), and as goal-like (or patient-like) to the extent that is has one or more of the goal (or patient) properties in (15b). These properties

17. In most work published so far, Bickel and Nichols use $\mathrm{O}$ instead of $\mathrm{P}$, but in more recent work (and in Witzlack-Makarevich 2011), P is used, so I use P in discussing the Bickelian approach here. 
are called "entailments", and they are largely taken from Dowty (1991) (see Witzlack-Makarevich 2011: Section 4.3 for detailed discussion).

a. Agent entailments:

causing an event (e.g., unemployment in unemployment causes delinquency)

volitional (e.g., she in she helped him)

sentient (e.g., she in she knew the answer)

existing independently of the event (e.g., he in he needs a new car)

b. Goal (or patient) entailments (Bickel et al. 2010: 384):

undergoing a change of state or in experience (him in give him something)

causally affected by another participant (it in cut it with something, load it with something)

stationary relative to movement of another participant (it in load it with something)

It is not quite clear whether these agent and goal/patient properties all have equal status, and what happens if the two arguments of the verb have an equal number of agent properties or goal/patient properties (e.g., in The room smells of apples in (9b), where independent existence seems to be the only relevant entailment, shared by both arguments). It also seems that these criteria cannot distinguish the two arguments of symmetrical verbs (e.g., French jouxter in (9a), wrestle with, etc.).

But apart from such (perhaps minor) issues, the most striking consequence of the Bickelian approach is that $\mathrm{A}$ and $\mathrm{P}$ (and also $\mathrm{T}$ and $\mathrm{G}$ ) are assigned to quite different kinds of arguments for different verb classes. In this way, they are like Dixonian A and $\mathrm{O}$, even though the unity of the latter is justified syntactically, not semantically. ${ }^{18}$ But since the arguments can be diverse syntactically as well, the "non-canonical" marking of A and P can be extreme: in an accusative language like German, $\mathrm{P}$ is in the Accusative case with verbs like umbringen 'kill' and schlagen 'beat', but is marked as a directional adverbial with movement verbs like gehen 'go', as a prepositional object with verbs like grauen (cf. 16b), is in the Dative with helfen-type verbs (cf. 10b), and is even in the Nominative case with verbs like gefallen (cf. 10a).

18. Dixon and Bickel would both say that der Junge in (10b) is an A, but for different reasons: Dixon because it behaves like other A arguments syntactically, Bickel because it has more agent entailments than dem Baby. 
With such a large amount of non-canonical marking, both the Dixonian and the Bickelian approach have to confront the question how useful it is to have concepts which are highly heterogeneous both formally and semantically. Often one accepts semantic heterogeneity associated with formal unity (e.g., polysemy), or formal heterogeneity with semantic unity (e.g., allomorphy). But the Bickelian A, P, G, and T are heterogeneous both semantically and formally. As a result of this heterogeneity, we end up saying that German has not just accusative, but also ergative alignment (because of experiential verbs of the gefallen class, which have a Nominative P), and Lezgian has not just ergative, but also accusative alignment (because of movement verbs of the 'go' type, which have an Absolutive A and a locational P). Such statements show that in practice, the Bickelian approach differs more drastically from the original Dixonian approach than the Comrian approach does. In effect, virtually all languages end up being "split-A" or "split-P" languages (i.e., languages with different coding of $\mathrm{A} / \mathrm{P}$ depending on the verb class).

At this point we should recall the purpose for which the SAPTR terms were originally created: to allow us to express perceived major typological differences, to state crosslinguistic generalizations, and to define further comparative concepts (as we saw in Section 1). But on the Bickelian approach, it is not straightforward to state the generalizations in (4) or to define the passive as in (5). In fact, Bickel \& Nichols (2009: 315) explicitly mention the possibility of $\mathrm{A}=\mathrm{P}$ alignment, which is ruled out by (4a), but which arises in their system with minor verb classes, such as the Latin pudet ('be ashamed') class, which takes an accusative experiencer (an accusative A in their terms). The Bickelian approach of looking at all verbs with the same numerical valency from a similar perspective is perfectly coherent, but one needs to ask how fruitful it is.

Bickel \& Nichols (2009: 308) themselves note: "The alignment patterns of chief typological interest are those that are the major or dominant or basic type in one or another language". Thus, while strictly speaking, German is not only accusative but also ergative, and Lezgian is not only ergative but also accusative, in practice typologists are interested primarily in the alignment of "major or dominant or basic" P with S. One can express this by saying that grammatical relations are characterized not only in terms of generalized semantic roles, but also in terms of predicate classes (as "conditions" on grammatical relations, Bickel 2011: 413-415). In German, the P of the major class is marked by Accusative case, the $\mathrm{P}$ of the helfen class is expressed by Dative case, and so on: 


\begin{tabular}{|c|c|c|}
\hline \multicolumn{3}{|c|}{ Two-argument verbs in German } \\
\hline A & $\mathrm{P}$ & \\
\hline Nom & Acc & $\begin{array}{l}\text { major/dominant/basic class (i.e., largest/most } \\
\text { productive) }\end{array}$ \\
\hline Nom & Dat & helfen class ('help', etc.) \\
\hline Dat & Nom & gefallen class ('please', etc.) \\
\hline Dat & $v o r+\mathrm{NP}_{\text {Dat }}$ & grauen class ('dread', etc.) \\
\hline
\end{tabular}

Thus, one could distinguish between $\mathrm{A}_{\text {major }}, \mathrm{A}_{\text {helfen }}, \mathrm{A}_{\text {gefallen }}$, and between $\mathrm{P}_{\text {major }}, \mathrm{P}_{\text {helfen }}, \mathrm{P}_{\text {grauen }}$, and so on. This would then allow us to express everything that is expressed by $\mathrm{A}$ and $\mathrm{P}$ in the Comrian approach by means of $\mathrm{A}_{\text {major }}$ and $\mathrm{P}_{\text {major }}$, i.e., $\mathrm{A}_{\text {major }}$ would be just a different notation for Comrian A. ${ }^{19}$

But at this point we must ask why we need $A$ and $P$ (and $T$ and $G$ ) as generalized semantic roles at all, i.e., why $\mathrm{A}_{\text {major }}$ and $\mathrm{P}_{\text {major }}$ are not sufficient. And here the answer seems to be that S, A, P, T, and G are not exclusively or even primarily conceived of as comparative concepts, but are intended to be used also for descriptive purposes. And to describe a language, one cannot limit oneself to the major verb classes. Both Nichols and Bickel have been influenced in their thinking by Foley \& Van Valin (1984), Van Valin (2005), who work with the semantic macroroles Actor (A) and Undergoer (U), and by Dowty (1991), who works with the protoroles Proto-Agent and Proto-Patient (and of course Foley \& Van Valin have been influenced by Dowty's earlier work, Dowty 1979). But Van Valin and Dowty are not primarily concerned with formulating crosslinguistic generalizations or alignment typologies, but with building an explicit descriptive framework for individual languages. Thus, they need descriptive categories, and comparative concepts are not sufficient for their purposes.

Be that as it may, the key question is how the definitions of $\mathrm{A}$ and $\mathrm{P}$ (and $\mathrm{T}$ and $\mathrm{G}$ ) given in (15) are motivated. Why use these seven semantic criteria, rather than fewer or more, or others? Bickel, Nichols, and WitzlackMakarevich do not say anything about this and just refer to Dowty (1991). But Dowty is not particularly interested in differences between languages, and in fact he is almost exclusively concerned with describing English subject-

19. There is another difference, because in the Bickelian approach, the "major" type is defined in terms of type frequency, not prototypicality. Witzlack-Makarevich (2011: Section 7.2) discusses the determination of the major class ("default class" in her terminology) in some detail, and ends up proposing that a language can be said to have a major class if the largest predicate class is at least ten percentage points larger than the second largest class. However, it is quite likely that in all languages, the class of physical effect verbs that Lazard characterizes as the most typical action verb class is the major class by this criterion, so that in practice, there would be no significant difference between the Comrian approach and the Bickelian approach here. 
object verbs (ignoring all other two-argument verbs, and ignoring languages that work differently). His lengthy discussion motivates the use of these criteria for English quite well, but one wonders why these very same criteria should be used for locational and experiential two-arguments and other languages as well. Another important question concerning (13) is how the decision to base the generalized semantic roles on numerical valency is motivated. Why are agent and patient entailments regarded as irrelevant for one-argument verbs? Dowty (1991: 605-613) applies his proto-roles to monovalent verbs as well, and many other authors (e.g., Foley \& Van Valin (1984), Kibrik (1997: 291), Primus (1999: 90-100), Mithun \& Chafe (1999: 576-579)) opt for generalized roles that capture the well-known similarities between transitive and intransitive agents/patients in the active-stative type (more on this type in Section 7 below).

Of course, there is a large amount of agreement among languages in treating typical physical effect verbs as the core of their major two-argument verb class (with A and P arguments), so the fact that Dowty's entailments are designed for the major two-argument verb class of English means that his Proto-Agent is quite similar to Comrie's A, and his Proto-Patient is quite similar to Comrie's P. But despite these similarities, Dowtyan proto-roles and Comrian comparative syntactic functions are quite different in nature. The former are designed to describe productive language-particular argument realization classes, while the latter are designed to capture salient crosslinguistic differences.

Before concluding this section, let us briefly consider Croft's (2001) characterization of the SAP terms, because like Bickel and associates, he defines S, $\mathrm{A}$, and $\mathrm{P}$ as generalized semantic roles (Croft 2001: 136):

[... ] the terms A, S, and P must be interpreted semantically. A, S and P each stand for a polysemous category made up of a cluster of semantic PARTICIPANT ROLES found in one-participant situations (S) and two-participant situations (A, $\mathrm{P})$.

Croft does not characterize $\mathrm{A}$ and $\mathrm{P}$ further, but the later discussion, where he introduces the additional notions Ex and St (for experiencer and stimulus), makes it clear that A and P only refer to typical agents and patients for him, and do not extend to experiencers and stimuli. And in Croft 1998: 51-52, A and $\mathrm{P}$ are used interchangeably with "subject" and "object", making it clear that $\mathrm{A}$ and $\mathrm{P}$ are not purely semantic notions. Thus, in Jane sprayed paint on the wall, paint is object/P, while in Jane sprayed the wall with paint, the wall is object/P (Croft 1998: 39). While Croft argues that this is actually a semantic alternation (Croft 1998: 44), and his A and P categories thus become as heterogenous semantically as Dowty's Proto-Agent and Proto-Patient, he emphasizes the role of physical effect events as the transitive prototype, much as in Comrie's, Andrews's, and Lazard's work (Croft 1998: 25, 53). Thus, Croft's 
approach is actually a variant of the Comrian approach, and quite unlike the Bickelian approach.

\section{On $\mathbf{T}$ and $\mathbf{R}$ in ditransitive clauses}

The first author to extend the spirit of the SAP terms to three-argument clauses was Croft (1990: 102-111), who followed Dryer's (1986) observation that the contrast between the indirective ("indirect-object") pattern ( $\mathrm{P}=\mathrm{T}$ vs. $\mathrm{R}$ ) and the secundative ("secondary-object") pattern ( $\mathrm{P}=\mathrm{R}$ vs. $\mathrm{T}$ ) is quite similar to the contrast between the ergative pattern and the accusative pattern. But Croft (1990) did not define $\mathrm{T}$ and $\mathrm{R}$ (in his notation, $\mathrm{G}$ ) other than saying that $\mathrm{T}$ is the "direct object" and R is the "indirect object" (taking these syntactic terms from French or English in an extended semantic sense, following much earlier usage). However, both Dryer's (1986) and Croft's (1990) examples make it clear that they mean verbs like 'give', 'bring', 'show', 'teach', and 'send', which in many languages are treated similarly; in other words, verbs of physical transfer of possession and verbs of mental transfer of experience. Other three-argument verbs, such as verbs of putting ('put', 'load', 'stick', 'wrap', 'cover'), or instrument verbs ('cut', 'saw', 'hit (with hand)', etc.) are never mentioned in this early seminal work, even though in some languages such verbs are treated much like transfer verbs. An example of the latter comes from Yoruba:
a. Bọ́lá fún adé ní ìwé.
Bola give Ade SEC book
'Bola gave Ade a book.' (Atoyebi et al. 2010: 145)
b. Ó gbá mi ní igi.
he hit me INS stick
'He hit me with a stick.' (Atoyebi et al. 2010: 149)

Just as A and P were defined in the Comrian approach as the agent and the patient of typical physical effect verbs, plus whatever arguments are treated in the same way, we may define $\mathrm{T}$ and $\mathrm{R}$ as the theme and the recipient of typical physical transfer verbs of possession ('give', 'lend', 'send', etc.), plus whatever arguments are treated in the same way. For example, the causee of a causative construction is often treated like the $\mathrm{R}$ of a physical transfer verb. We may then say that the causative is formed as in (19a) in terms of R and T, similarly to what we would say about passives and locative applicatives in terms of A, S, and P:
a. Causative: $\quad \mathrm{X}_{\mathrm{A}}-\mathrm{Y}_{\mathrm{P}}>\mathrm{Z}_{\mathrm{A}}-\mathrm{X}_{\mathrm{R}}-\mathrm{Y}_{\mathrm{T}}$
b. Passive: $\quad \mathrm{X}_{\mathrm{A}}-\mathrm{Y}_{\mathrm{P}}>\mathrm{Y}_{\mathrm{S}}-\mathrm{X}_{\mathrm{obl}}$
c. Applicative: $\mathrm{X}_{\mathrm{S}}-\mathrm{Y}_{\mathrm{loc}}>\mathrm{X}_{\mathrm{A}}-\mathrm{Y}_{\mathrm{P}}$ 
And again as with two-argument clauses, we can define "ditransitive" in terms of $\mathrm{R}$ and $\mathrm{T}$, rather than defining (in Dixonian manner) $\mathrm{R}$ and $\mathrm{T}$ in terms of "ditransitive".

However, how well-motivated is the decision to focus on physical transfer verbs as the basis for the definition of T and R? In the case of A and P, Andrews and Lazard noted that apparently in all languages, all typical physical action verbs behave alike, and in all languages there is a substantial class of verbs that behave in this way, often going significantly beyond the class of physical action verbs (this is probably even the major two-argument class in all languages).

With three-argument verbs, we can neither say with confidence that physical transfer verbs of possession tend to be the major class, nor that all physical transfer verbs behave in the same way. Languages do not have a large number of physical transfer verbs of possession, and verbs of putting and instrumental verbs, where both non-agent arguments are inanimate, are quite diverse as well. Moreover, even within the class of physical transfer verbs, there tends to be more variation than within the class of physical effect verbs. In English, too, some verbs have multiple coding patterns:

a. They supplied the street dealers with drugs.

b. They supplied drugs to the street dealers.

It has been noted repeatedly that the most frequent physical transfer verb, 'give', is often quite unique in its grammatical behaviour (Comrie \& Borg 1984, Kittilä 2006). On the other hand, it does seem to be the case that physical transfer verbs of possession tend to be much more frequent in texts than other three-argument verbs, so that at least from this point of view, there is good justification for a definition of $\mathrm{R}$ and $\mathrm{T}$ in these terms. It should also be noted that in many languages, 'give' is a high-frequency verb, far more frequent than any other three-argument verb. This may justify the strategy of defining $\mathrm{R}$ and $\mathrm{T}$ in even narrower terms, as the recipient and gift of 'give' (cf. Haspelmath 2005a, b), even though this will not solve the problem of splits entirely, because some languages have different 'give' verbs with different coding patterns.

Be that as it may, we have to accept that the comparative concepts $\mathrm{R}$ and $\mathrm{T}$ do not capture the same range of phenomena as the concepts $\mathrm{A}$ and $\mathrm{P}$, and are thus much less significant, in the sense that if we characterize typological differences between languages in terms of $\mathrm{T}$ and $\mathrm{R}$, we say less about the languages than if we talk about A and P. While it is probably fair to say that ergative and absolutive (defined in terms of A and P) are "major alignment types", we are less justified in saying that alignment in terms of $\mathrm{T}$ and $\mathrm{R}$ (defined as theme and recipient of typical physical transfer verbs like 'give') are "major" in this sense (cf. the section heading of Section 1 of Haspelmath 2005a, where this term is used). 
But the fact that ditransitive alignment in terms of $\mathrm{T}$ and $\mathrm{R}$ cannot be characterized as "major" does not make these concepts incoherent or irrelevant. As Lazard $(2002,2006)$ emphasized, comparative concepts can be regarded as "arbitrary conceptual frameworks", whose usefulness is to be judged by the fruitfulness of the generalizations emerging from studies based on these concepts. And it seems difficult to deny that typological research based on $\mathrm{T}$ and R (such as Siewierska 2003, 2004; Haspelmath 2005a; Malchukov et al. 2010) has been fruitful.

The question that must be asked, however, is whether there is an alternative to $\mathrm{R}$ and $\mathrm{T}$ in Croft's and Dryer's sense that is superior in that it allows us to express even more generalizations. This does not seem to be the case, however. The Bickelian alternative of defining $\mathrm{G}$ as the more goal-like/patient-like and $\mathrm{T}$ as the less goal-like/patient-like argument of the less agent-like arguments leads to an even more heterogeneous class of arguments (see 14c, d), and to fewer chances of finding crosslinguistic generalizations. The problems with Bickelian $\mathrm{G}$ and $\mathrm{T}$ are completely analogous to the problems with their $\mathrm{A}$ and $\mathrm{O}$, so they need not be repeated here.

\section{On the $S$ argument of intransitive clauses}

We saw in Section 4 that $\mathrm{S}$ can best be defined as the argument of an intransitive clause that receives the treatment normally accorded to the single argument of a one-argument predicate. But as is well known (Mithun 1991, Donohue \& Wichmann (eds.) 2008), in many languages the single argument of a oneargument predicate is treated differently in different verb classes. Often one subclass of (the more patient-like) $\mathrm{S}$ arguments is treated like the $\mathrm{P}$, while another subclass of (more agent-like) S arguments is treated like the A. In other languages, a subclass of (experiencer) $\mathrm{S}$ arguments is treated like the $\mathrm{R}$ argument of ditransitive clauses. In the typological literature, the two subclasses of $\mathrm{S}$ are sometimes distinguished as $\mathrm{S}_{\mathrm{A}}$ vs. $\mathrm{S}_{\mathrm{P}}$ (or $\mathrm{S}_{\mathrm{O}}$, Dixon 1994: 70-83).

Is the concept of $\mathrm{S}$ incoherent in view of such "split-S" languages? Harris (1997: 368) argues that in view of languages like Georgian (with some singleargument verbs requiring Ergative marking, and others Nominative marking), $\mathrm{S}_{\mathrm{A}}$ and $\mathrm{S}_{\mathrm{P}}$ need to be regarded as primitives, rather than as subtypes of $\mathrm{S}$ (as Dixon does). Just as Dixon has posited S, A, and $\mathrm{O}$ as primitives in order to avoid describing ergative patterns as "twisted versions of accusative patterns", Harris notes, one needs to work with $S_{A}$ and $S_{P}$ as primitives in order to avoid describing Georgian as a twisted version of an ergative or an accusative language. Or as Mithun \& Chafe (1999: 578) put it: "Speakers of Iroquoian languages could say with equal justification that English is a 'split patient' language, since English sometimes marks patients as subjects, sometimes as objects". 
But Harris and Mithun \& Chafe (like Dixon) do not distinguish properly between the descriptive level and the comparative level. As we saw earlier, to describe Georgian and Iroquoian, we need semantic roles only to the extent that there are open, productive verb classes that can be extended only by verbs of a certain semantic character. But to compare Georgian and Iroquoian with other languages, both approaches are perfectly coherent. The difference between them is comparable to the difference between the Comrian and the Bickelian approach to A and P in two-argument clauses: where Comrie limits the "primitives" A and P to a subclass of two-argument verbs, Bickel uses two "primitives" A and P for all two-argument verbs alike. Both approaches are coherent, but I have argued above that the Comrian approach makes it easier to state certain generalizations.

With Bickelian A and P, practically all languages are "split-P" languages and many languages are "split-A" languages, because few (if any) languages extend their major two-argument pattern to all two-argument clauses. Similarly, the decision to look at all $\mathrm{S}$ arguments together leads to a situation where many languages are "split-S" languages.

In the Comrian spirit, it would therefore be desirable to focus on a subclass of intransitive single arguments which show more uniformity across languages than the class of single intransitive verbs as a whole. A good candidate is the subclass of uncontrolled change of state verbs like 'die', 'rust', 'get lost', 'rot', 'grow' (typical unaccusative verbs, cf. Croft 1998: 52-54). Should it turn out that there is significant variation even within this subclass, one might adopt the strategy of choosing only the verb 'die', as the most typical (and probably most frequent) uncontrolled change of state verb (just as for ditransitives, some authors have limited themselves to the verb 'give'). So I tentatively propose that the original unitary $S$ should be replaced by $S_{U}$ (where $U$ stands for 'uncontrolled change of state'; cf. also Creissels's (2006: 300) U, proposed to replace S).

Clearly, a narrowing strategy of this sort has generally been adopted implicitly in the literature, because most discussions of split-S systems (e.g., Merlan 1985, Lazard 1986, Mithun 1991, Croft 1998, Arkadiev 2008) have not taken all monovalent verbs in account, and have completely ignored experiential single-argument verbs with dative or accusative experiencers (of the type mich friert in German). With the notable exception of Nichols (2008) (who works in the Bickelian approach), work on split-S patterns has focused on agentive/patientive monovalents and ignored experiential monovalents, just as experiential constructions have usually been left aside in discussions of twoargument patterns, because it is generally understood that something else is going on there. The idea that one should focus on $S_{U}$ takes this approach to its logical conclusion. As a consequence, the active-stative type is no longer a monotransitive alignment type on a par with ergative and accusative, but is 
dealt with separately, just as the treatment of experiential constructions is not generally subsumed under monotransitive alignment.

\section{Conclusion}

In this article, I have compared three main ways in which the terms S, A, P, T, and $\mathrm{R}$ (and their notational variants) have been used. I began by noting that they were introduced primarily in order to allow us to compare different languages in terms of their alignment, and in order to be able to state generalizations and to define further comparative concepts such as "passive".

The first claim of this article is that there are three rather distinct ways in which the terms have been used in the literature: as universal syntactic functions based on transitivity (the Dixonian approach), as comparative concepts for the two arguments of a typical action clause (the Comrian approach), and as generalized semantic roles (the Bickelian approach).

The second claim is that the Comrian approach is best suited for the statement of crosslinguistic generalizations in the domain of classical alignment phenomena. It is not based on a notion of transitivity and thus allows us to define (MONO)TRANSITIVE on the basis of A and P (and DITRANSITIVE on the basis of $\mathrm{T}$ and $\mathrm{R}$ ); this is superior to the Dixonian approach, where transitivity is not properly defined. The Comrian approach to A and $\mathrm{P}$ is also superior to the Bickelian approach, because typical action clauses behave very uniformly in all languages, so that there are very few (if any) "split-A" and "split-P" languages. On the much broader Bickelian definition of $\mathrm{A}$ and $\mathrm{P}$, almost all languages are "split-P" and many languages are "split-A" languages. To capture the traditional generalizations of alignment typology, the Bickelian approach needs to appeal to narrower concepts such as $\mathrm{P}_{\text {major }}$ (the $\mathrm{P}$ of the major class of two-argument verbs). To what extent the broader notions of $\mathrm{A}$ and $\mathrm{P}$ might be useful in typology remains to be seen.

Both the Dixonian and the Bickelian approach seem to be interested not only in alignment typology, i.e., in the SAPTR terms as comparative concepts, but also in providing general terms for describing particular languages, i.e., universally applicable descriptive categories. The idea of creating a finite set of concepts that can be used both for language description and for language comparison also underlies technological approaches such as the GOLD ontology (Farrar \& Langendoen 2003), as well as much of generative grammar (Newmeyer 2007), but languages are simply too diverse for this approach to be feasible (Lazard 1992; Croft 2001; Haspelmath 2007, 2010).

Thus, typology generally has to be content to capture only some aspects of language structure (e.g., only the major class of two-argument verbs), whereas language description needs to be complete. But this does not mean that typology cannot gradually enlarge its purview. By focusing on typical action verbs, 
typologists have generally neglected other kinds of two-argument verbs, and there is no reason not to add further comparative concepts such as Ex (for the experiencer of typical experiential verbs), St (for the stimulus of typical experiential verbs), Go (for the spatial goal of directional movement verbs), and so on, in future work.

One final lesson that can be drawn from this article is that linguistic terms have a tendency to undergo significant semantic change when they migrate from one scholar to another, or from one way of thinking to another. This is perhaps unavoidable, but it is useful to be explicit not only about the meanings of terms, but also about changes in their meanings.

Received: 21 April 2011

Revised: 29 August 2011
Max-Planck-Institut für evolutionäre Anthropologie

Correspondence address: Department of Linguistics, Max-Planck-Institut für evolutionäre Anthropologie, 04103 Leipzig, Germany; e-mail: haspelmath@eva.mpg.de

Acknowledgements: I am grateful to audiences at the Max Planck Institute for Evolutionary Anthropology and at the University of Zurich workshop on Semantic Role Complexes (April 2011) for useful comments. In particular, I thank Balthasar Bickel and Alena Witzlack-Makarevich for helpful discussion. It was their highly interesting and challenging work that inspired me to put these thoughts on paper.

Abbreviations: ABS absolutive; ACC accusative; ADESS adessive; AOR aorist; APPL applicative; ART article; DAT dative; DU dual; ERG ergative; GEN genitive; IMPF imperfective; INS instrumental; NEG negation; NOM nominative; PL plural; POEL postelative; PST past; SEC secundative.

\section{References}

Aikhenvald, Alexandra Y. 2003. A grammar of Tariana. Cambridge: Cambridge University Press.

Aikhenvald, Alexandra Y., R. M. W. Dixon \& Masayuki Onishi (eds.). 2001. Non-canonical marking of subjects and objects. Amsterdam: Benjamins.

Anderson, Stephen. 1976. On the notion of subject in ergative languages. In Li (ed.), 1-24.

Andrews, Avery. 1985. The major functions of the noun phrase. In Timothy Shopen (ed.), Language typology and syntactic description, Vol. 1: Clause structure, 62-154. Cambridge: Cambridge University Press.

Andrews, Avery D. 2001. Non-canonical A/S marking in Icelandic. In Aikhenvald et al. (eds.) 2001, 85-111.

Andrews, Avery D. 2007. The major functions of the noun phrase. In Shopen (ed.) 2007, 132-223.

Arkadiev, Peter M. 2008. Thematic roles, event structure, and argument encoding in semantically aligned languages. In Donohue \& Wichmann (eds.) 2008, 101-117.

Atoyebi, Joseph Dele, Martin Haspelmath, \& Andrej Malchukov. 2010. Ditransitive constructions in Yorùbá. In Malchukov et al. (eds.) 2010, 145-165.

Bickel, Balthasar. 2011. Grammatical relations typology. In Jae Jung Song (ed.), The Oxford handbook of linguistic typology, 399-444. Oxford: Oxford University Press.

Bickel, Balthasar \& Johanna Nichols. 2009. Case marking and alignment. In Malchukov \& Spencer (eds.) 2009, 304-321.

Bickel, Balthasar, Manoj Rai, Netra P. Paudyal, Goma Banjade, Toya N. Bhatta, Martin Gaenszle, Elena Lieven, Ichchha Purna Rai, Novel Kishore Rai \& Sabine Stoll. 2010. The syntax of 
three-argument verbs in Chintang and Belhare (Southeastern Kiranti). In Malchukov et al. (eds.) 2010, 382-408.

Blake, Barry J. 1976. On ergativity and the notion of subject: Some Australian cases. Lingua 39. 281-300.

Blake, Barry J. 1977. Case marking in Australian languages. Canberra: Australian Institute of Aboriginal Studies.

Blake, Barry J. 1990. Relational grammar. London: Routledge.

Blake, Barry J. 1994. Case. Cambridge: Cambridge University Press.

Bossong, Georg. 1998. Le marquage de l'expérient dans les langues d'Europe. In Feuillet (ed.) 1998, 259-294.

Bresnan, Joan. 2001. Lexical-Functional Syntax. Oxford: Blackwell.

Comrie, Bernard. 1978. Ergativity. In Winfred P. Lehmann (ed.), Syntactic typology: Studies in the phenomenology of language, 329-394. Austin: University of Texas Press.

Comrie, Bernard. 1981. Language universals and linguistic typology: Syntax and morphology. Oxford: Blackwell.

Comrie, Bernard. 1989. Language universals and linguistic typology: Syntax and morphology. 2nd edn. Oxford: Blackwell.

Comrie, Bernard. 2005. Alignment of case marking. In Haspelmath et al. (eds.) 2005, 398-405.

Comrie, Bernard \& Albert Borg. 1984. Object diffuseness in Maltese. In Frans Plank (ed.), Objects: Towards a theory of grammatical relations, 109-126. New York: Academic Press.

Creissels, Denis. 2006. Syntaxe générale, une introduction typologique. 2 vols. Paris: LavoisierHermès Science.

Croft, William. 1990. Typology and universals. Cambridge: Cambridge University Press.

Croft, William. 1998. Event structure in argument linking. In Miriam Butt \& Wilhelm Geuder (eds.), The projection of parameters, 21-63. Stanford, CA: CSLI.

Croft, William. 2001. Radical construction grammar: Syntactic theory in typological perspective. Oxford: Oxford University Press.

Croft, William. 2003. Typology and universals. 2nd edn. Cambridge: Cambridge University Press.

Davidse, Kristin \& Béatrice Lamiroy (eds.). 2002. The nominative \& accusative and their counterparts. Amsterdam: Benjamins.

Dik, Simon C. 1997. The theory of Functional Grammar. 2 vols. Berlin: Mouton de Gruyter.

Dixon, R. M. W. 1968. The Dyirbal language of north Queensland. London: University of London doctoral dissertation.

Dixon, R. M.W. 1972. The Dyirbal language of north Queensland. Cambridge: Cambridge University Press.

Dixon, R. M. W. 1979. Ergativity. Language 55. 59-138.

Dixon, R. M. W. 1988. A grammar of Boumaa Fijian. Chicago: University of Chicago Press.

Dixon, R. M. W. 1994. Ergativity. Cambridge: Cambridge University Press.

Dixon, R. M. W. 2000. A typology of causatives: Form, syntax and meaning. In R. M. W. Dixon \& Alexandra Y. Aikhenvald (eds.), Changing valency: Case studies in transitivity, 30-83. Cambridge: Cambridge University Press.

Dixon, R. M. W. 2010a. Basic linguistic theory, Vol. 1: Methodology. Oxford: Oxford University Press.

Dixon, R. M. W. 2010b. Basic linguistic theory, Vol. 2: Grammatical topics. Oxford: Oxford University Press.

Dixon, R. M. W. with Alan R. Vogel. 2004. The Jarawara language of southern Amazonia. Oxford: Oxford University Press.

Donaldson, Tamsin. 1980. Ngiyambaa: The language of the Wangaaybuwan. Cambridge: Cambridge University Press.

Donohue, Mark. 1999. A grammar of Tukang Besi. Berlin: Mouton de Gruyter.

Donohue, Mark \& Søren Wichmann (eds.). 2008. The typology of semantic alignment. Oxford: Oxford University Press. 
Dowty, David R. 1979. Word meaning and Montague grammar. Dordrecht: Reidel.

Dowty, David R. 1991. Thematic proto-roles and argument selection. Language 67. 547-619.

Dryer, Matthew S. 1986. Primary objects, secondary objects, and antidative. Language 62. 808845.

Dryer, Matthew S. 1997. Are grammatical relations universal? In Joan L. Bybee, John Haiman \& Sandra A. Thompson (eds.), Essays on language function and language type: Dedicated to T. Givón, 115-143. Amsterdam: Benjamins.

Dryer, Matthew S. 2007. Clause types. In Shopen (ed.) 2007, 224-275.

Engel, Ulrich. 1988. Deutsche Grammatik. Heidelberg: Groos.

Falk, Yehuda. 2006. Subjects and universal grammar: An explanatory theory. Cambridge: Cambridge University Press.

Farrar, Scott \& D. Terence Langendoen. 2003. A linguistic ontology for the semantic web. Glot International 7. 97-100.

Farrell, Patrick. 2005. Grammatical relations. Oxford: Oxford University Press.

Feuillet, Jacques (ed.). 1998. Actance et valence dans les langues de l'Europe. Berlin: Mouton de Gruyter.

Fillmore, Charles J. 1968. The case for case. In Emmon Bach \& Robert T. Harms (eds.), Universals in linguistic theory, 1-88. New York: Holt, Rinehart \& Winston.

Foley, William A. \& Robert D. Van Valin, Jr. 1977. On the viability of the notion of 'subject' in universal grammar. Berkeley Linguistics Society 3. 293-320.

Foley, William A. \& Robert D. Van Valin, Jr. 1984. Functional syntax and universal grammar. Cambridge: Cambridge University Press.

Goddard, Cliff. 1982. Case systems and case marking in Australian languages: A new interpretation. Australian Journal of Linguistics 2. 167-196.

Guillaume, Antoine. 2008. A grammar of Cavineña. Berlin: Mouton de Gruyter.

Harris, Alice C. 1997. Review of Dixon 1997. Language 73. 359-374.

Haspelmath, Martin. 2005a. Argument marking in ditransitive alignment types. Linguistic Discovery 3. 1-21.

Haspelmath, Martin. 2005b. Ditransitive constructions: The verb 'give'. In Haspelmath et al. (eds.) 2005, 426-429.

Haspelmath, Martin. 2007. Pre-established categories don't exist: Consequences for language description and typology. Linguistic Typology 11. 119-132.

Haspelmath, Martin. 2009. Terminology of case. In Malchukov \& Spencer (eds.) 2009, 505-517.

Haspelmath, Martin. 2010. Comparative concepts and descriptive categories in crosslinguistic studies. Language 86. 663-687.

Haspelmath, Martin, Matthew S. Dryer, David Gil \& Bernard Comrie (eds.). 2005. The world atlas of language structures. Oxford: Oxford University Press.

Hopper, Paul J. \& Sandra A. Thompson. 1980. Transitivity in grammar and discourse. Language 56. 251-299.

Kibrik, Aleksandr E. 1997. Beyond subject and object: Toward a comprehensive relational typology. Linguistic Typology 1. 279-346.

Kittilä, Seppo. 2002. Remarks on the basic transitive sentence. Language Sciences 24. 107-130.

Kittilä, Seppo. 2006. The anomaly of the verb 'give' explained by its high (formal and semantic) transitivity. Linguistics 44. 569-612.

Koptjevskaja-Tamm, Maria. 1993. Nominalizations. London: Routledge.

Kruspe, Nicole. 2004. A grammar of Semelai. Cambridge: Cambridge University Press.

Lazard, Gilbert. 1978. Eléments d'une typologie des structures d'actance: Structures ergatives accusatives et autres. Bulletin de la Société de Linguistique de Paris 73(1). 49-84.

Lazard, Gilbert. 1992. Y at-il des catégories interlangagières? In Susanne Anschütz (ed.), Texte, Sätze, Wörter und Moneme: Festschrift für Klaus Heger, 427-434. Heidelberg: Orientverlag.

Lazard, Gilbert. 1994. L'actance. Paris: Presses universitaires de France.

Lazard, Gilbert. 1997. Ergativity. Review of Dixon (1994). Linguistic Typology 1. 243-268. 
Lazard, Gilbert. 1998. Définition des actants dans les langues européennes. In Feuillet (ed.) 1998, $11-146$.

Lazard, Gilbert. 2002. Transitivity revisited as an example of a more strict approach in typological research. Folia Linguistica 36. 141-190.

Lazard, Gilbert. 2006. La quête des invariants interlangues: La linguistique est-elle une science? Paris: Champion.

Li, Charles (ed.). 1976. Subject and topic. New York: Academic Press.

Malchukov, Andrej L. 2005. Case pattern splits, verb types and construction competition. In Mengistu Amberber \& Helen de Hoop (eds.), Competition and variation in natural languages: The case for case, 73-118. Oxford: Elsevier.

Malchukov, Andrej L., Martin Haspelmath, \& Bernard Comrie. 2010. Ditransitive construction: A typological overview. In Malchukov et al. (eds.) 2010, 1-64.

Malchukov, Andrej L., Martin Haspelmath, \& Bernard Comrie (eds.). 2010. Studies in ditransitive constructions: A comparative handbook. Berlin: De Gruyter Mouton.

Malchukov, Andrej L. \& Andrew Spencer (eds.). 2009. The Oxford handbook of case. Oxford: Oxford University Press.

Mallinson, Graham \& Barry J. Blake. 1981. Language typology: Cross-linguistic studies in syntax. Amsterdam: North-Holland.

McGregor, William. 2002. Ergative and accusative patterning in Warrwa. In Davidse \& Lamiroy (eds.) 2002, 285-317.

Melis, Ludo. 2002. Objects and quasi-objects: The constellation of the object in French. In Davidse \& Lamiroy (eds.) 2002, 41-79.

Merlan, Francesca. 1985. Split intransitivity: Functional oppositions in intransitive inflection. In Johanna Nichols \& Anthony Woodbury (eds.), Grammar inside and outside the clause: Approaches to theory from the field, 324-362. Cambridge: Cambridge University Press.

Mithun, Marianne. 1991. Active/agentive case marking and its motivations. Language 67. 510546.

Mithun, Marianne \& Wallace Chafe. 1999. What are S, A, and O? Studies in Language 23. 569596.

Næss, Åshild. 2007. Prototypical transitivity. Amsterdam: Benjamins.

Newmeyer, Frederick J. 2007. Linguistic typology requires crosslinguistic formal categories. Linguistic Typology 11. 133-157.

Nichols, Johanna. 1992. Linguistic diversity in space and time. Chicago: University of Chicago Press.

Nichols, Johanna. 2008. Why are stative-active languages rare in Eurasia? A typological perspective on split-subject marking. In Donohue \& Wichmann (eds.) 2008, 121-140.

Onishi, Masayuki. 2001. Non-canonically marked subjects and objects: Parameters and properties. In Aikhenvald et al. (eds.) 2001, 1-51.

Palmer, F. R. 1994. Grammatical roles and relations. Cambridge: Cambridge University Press.

Payne, Thomas. 1997. Describing morphosyntax: A guide for field linguists. Cambridge: Cambridge University Press.

Perlmutter, David M. 1980. Relational grammar. In Edith A. Moravcsik \& Jessica R. Wirth (eds.), Current approaches to syntax (Syntax and Semantics 13), 195-229. New York: Academic Press.

Plank, Frans. 1979. Ergativity, syntactic typology and universal grammar: Some past and present viewpoints. In Frans Plank (ed.), Ergativity: Towards a theory of grammatical relations, 336. New York: Academic Press.

Primus, Beatrice. 1999. Cases and thematic roles: Ergative, accusative and active. Tübingen: Niemeyer.

Reis, Marga. 1982. Zum Subjektbegriff im Deutschen. In Werner Abraham (ed.), Satzglieder im Deutschen: Vorschläge zur syntaktischen, semantischen und pragmatischen Fundierung, 171-212. Tübingen: Narr. 
Schachter, Paul. 1976. The subject in Philippine languages: Topic, actor, actor-topic, or none of the above. In Li (ed.) 1976, 491-518.

Schapper, Antoinette. 2009. Bunaq: A Papuan language of central Timor. Canberra: Australian National University doctoral dissertation.

Shopen, Timothy (ed.). 2007. Language typology and syntactic description, Vol. 1: Clause structure. 2nd edn. Cambridge: Cambridge University Press.

Siewierska, Anna. 1984. The passive: A comparative linguistic analysis. London: Croom Helm.

Siewierska, Anna. 2003. Person agreement and the determination of alignment. Transactions of the Philological Society 101. 339-370.

Siewierska, Anna. 2004. Person. Cambridge: Cambridge University Press.

Tesnière, Lucien. 1959. Eléments de syntaxe structurale. Paris: Klincksieck.

Tsunoda, Tasaku. 1985. Remarks on transitivity. Journal of Linguistics 21. 385-396.

Van Valin, Robert D., Jr. 2005. Exploring the syntax-semantics interface. Cambridge: Cambridge University Press.

Whaley, Lindsay. 1997. Introduction to typology: The unity and diversity of language. Thousand Oaks, CA: Sage.

Witzlack-Makarevich, Alena. 2011. Typological variation in grammatical relations. Leipzig: Universität Leipzig doctoral dissertation. 